\title{
Managing Patients With Heart Failure: A Qualitative Study of Multidisciplinary Teams With Specialist Heart Failure Nurses
}

\author{
Margaret Glogowska, $\mathrm{PbD}^{1}$ \\ Rosemary Simmonds, $\mathrm{MSc}^{2}$ \\ Sarab McLacblan, $P b D^{3}$ \\ Helen Cramer, $P b D^{2}$ \\ Tom Sanders, $P b D^{4}$ \\ Racbel Jobnson, $B M B C b^{2}$ \\ Umesh T. Kadam, $\mathrm{PbD}^{3}$ \\ Daniel S. Lasserson, $M D^{1}$ \\ Sarab Purdy, $M D^{2}$ \\ 'University of Oxford, Oxford, \\ United Kingdom \\ ${ }^{2}$ University of Bristol, Bristol, \\ United Kingdom \\ ${ }^{3}$ University of Keele, Keele, \\ United Kingdom \\ ${ }^{4}$ University of Sheffield, Sheffield, \\ United Kingdom
}

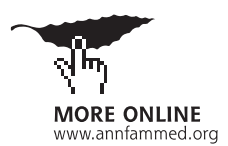

Conflicts of interest: authors report none.

\section{CORRESPONDING AUTHOR}

Margaret Glogowska, $\mathrm{PhD}$

Nuffield Department of Primary Care Health Sciences

University of Oxford

New Radcliffe House

Radcliffe Observatory Quarter

Woodstock Road, Oxford OX2 6GG

Margaret.glogowska@phc.ox.ac.uk

\begin{abstract}
PURPOSE The purpose of this study was to explore the perceptions and experiences of health care clinicians working in multidisciplinary teams that include specialist heart failure nurses when caring for the management of heart failure patients.
\end{abstract}

METHODS We used a qualitative in-depth interview study nested in a broader ethnographic study of unplanned admissions in heart failure patients (HoldFAST). We interviewed 24 clinicians across primary, secondary, and community care in 3 locations in the Midlands, South Central, and South West of England.

RESULTS Within a framework of the role and contribution of the heart failure specialist nurse, our study identified 2 thematic areas that the clinicians agreed still represent particular challenges when working with heart failure patients. The first was communication with patients, in particular explaining the diagnosis and helping patients to understand the condition. The participants recognized that such communication was most effective when they had a long-term relationship with patients and families and that the specialist nurse played an important part in achieving this relationship. The second was communication within the team. Multidisciplinary input was especially needed because of the complexity of many patients and issues around medications, and the participants believed the specialist nurse may facilitate team communication.

CONCLUSIONS The study highlights the role of specialist heart failure nurses in delivering education tailored to patients and facilitating better liaison among all clinicians, particularly when dealing with the management of comorbidities and drug regimens. The way in which specialist nurses were able to be caseworkers for their patients was perceived as a method of ensuring coordination and continuity of care.

Ann Fam Med 2015;13:466-471. doi: 10.1370/afm.1845.

\section{INTRODUCTION}

$\mathrm{H}$ eart failure is a common disorder, particularly among older people. ${ }^{1}$ It is associated with high morbidity, poor prognosis, ${ }^{2}$ and a survival rate worse than that for some cancers. ${ }^{3}$ It places a heavy burden on patients and their families ${ }^{3,4}$ and on health care resources, accounting for high numbers of unplanned hospital admissions. ${ }^{5}$

Management of patients with heart failure involves health care clinicians who work in the community and in hospitals. In the community, primary care is delivered by general practitioners; increasingly they are supported by community-based specialist nurses whose role has developed in recent years. ${ }^{6,7}$ In secondary care, patients with heart failure can be managed on an outpatient basis for a new diagnosis or by monitoring whether the patients are clinically stable, with their care usually undertaken by cardiologists or geriatricians. For patients requiring hospital admission with acute severe symptoms from heart failure, acute general medical physicians in the United Kingdom initially manage the hospital- 
based care, and they are supported where necessary by cardiologists.

To date, studies of clinicians working with heart failure patients have often been quantitative. These studies have tended to explore decision making in primary care around diagnosis and treatment, ${ }^{8,9}$ and with the implementation of evidence-based clinical guidelines, particularly with regard to medications. ${ }^{10,11}$ The qualitative literature has reported issues regarding diagnosis, ${ }^{12}$ treatment in primary care, ${ }_{1}^{13}$ and barriers to communication between heart failure patients and primary care clinicians. ${ }^{14,15}$ Since the inception of specialist heart failure nursing services, research has been conducted into their effectiveness ${ }^{16}$ and how they are perceived by other clinicians.$^{17}$ There is little knowledge, however, of clinicians' experiences of working in multidisciplinary teams and the role that specialist heart failure nurses play. Specialist heart failure nurses are experienced senior nurses whose involvement with patients begins at the initial diagnosis of heart failure and continues for the course of a patient's illness. They provide medical, psychological, and emotional support and may be able to visit patients on a regular basis at home.

The study reported here was part of a wider investigation into unplanned hospital admissions. In this article we focus on the experiences and perceptions of clinicians as they manage patients with heart failure. Our objective was, by using in-depth interviews, to gain an understanding of the issues facing clinicians as they care for this patient group in the light of recent developments, including the introduction of specialist heart failure nurses.

\section{METHODS}

\section{Sampling and Data Collection}

Clinician interviews took place in 3 geographical locations in the United Kingdom where patients with severe or difficult-to-manage heart failure were participating in a wider, multicenter ethnographic study of unplanned hospital admission for heart failure (HoldFAST). The research was approved by the National Health Service Health Research Authority Research Ethics Committee South West (REC reference 12/SW/0104).

We sought to interview a wide range of clinicians involved in caring for the patients participating in HoldFAST. We used purposive sampling to ensure that the perspectives of clinicians from primary, specialty (secondary), and community care were included (Table 1). In-depth interviews took place in the clinicians' workplaces wherever possible. The clinicians received information about the study and gave written informed consent. We used a topic guide to ensure coverage of areas relevant to the research questions but allowed participants to raise their own issues. (The interview topic guide is available as a Supplemental Appendix at http://www.annfammed. org/content/13/5/466/suppl/DC1.) In each location, new issues that arose from the interviews were carried forward into subsequent interviews. Because data collection was taking place at 3 locations simultaneously, we did not intentionally monitor for a point at which data saturation was reached. When we stopped interviewing, however, no new themes were emerging.

\section{Data Analysis}

Analysis was informed by the constant comparative method, ${ }_{1}^{18,19}$ which included familiarization with the transcripts, sketching out initial themes, and conducting systematic open coding using NVivo 10 qualitative data analysis software (QRS International). The coding of the first set of interviews (from 1 location) generated

\begin{tabular}{|c|c|c|}
\hline $\begin{array}{l}\text { Staff Based in } \\
\text { Primary Care }\end{array}$ & Staff Based in Specialty Care & $\begin{array}{l}\text { Staff Based in } \\
\text { Community Care }\end{array}$ \\
\hline \multicolumn{3}{|l|}{ Location 1 (South West) } \\
\hline \multicolumn{3}{|c|}{$\begin{array}{l}\text { Two separate hospitals provide outpatient heart failure clinics; community specialist heart failure } \\
\text { nurses see patients with heart failure of any type, but their capacity is limited. }\end{array}$} \\
\hline General practitioner (P1) & Cardiologist (P8) & \multirow{2}{*}{$\begin{array}{l}\text { Specialist heart failure } \\
\text { nurse (P20) }\end{array}$} \\
\hline General practitioner (P2) & Geriatrician (P9) & \\
\hline General practitioner (P3) & Hospital liaison psychiatrist (P10) & \multirow{2}{*}{ Community matron (P21) } \\
\hline \multicolumn{2}{|l|}{$\begin{array}{l}\text { General practitioner } \\
\text { (interviewed twice) (P4) }\end{array}$} & \\
\hline \multicolumn{3}{|l|}{ Location 2 (South Central) } \\
\hline \multicolumn{3}{|c|}{$\begin{array}{l}\text { One hospital provides outpatient clinics with community specialist heart failure nurses seeing } \\
\text { patients with left ventricular systolic dysfunction (LVSD) only. }\end{array}$} \\
\hline General practitioner (P5) & Cardiologist (P11) & \multirow{4}{*}{$\begin{array}{l}\text { Specialist heart failure } \\
\text { nurses (interviewed } \\
\text { together) (P22 and 23) }\end{array}$} \\
\hline \multirow[t]{3}{*}{ General practitioner (P6) } & $\begin{array}{l}\text { Specialist heart failure nurses (inter- } \\
\text { viewed together) (P12 and 13) }\end{array}$ & \\
\hline & Heart failure specialist nurse (P14) & \\
\hline & Cardiac Rehabilitation manager ${ }^{\mathrm{a}}$ (P15) & \\
\hline \multicolumn{3}{|l|}{ Location 3 (Midlands) } \\
\hline \multicolumn{3}{|c|}{$\begin{array}{l}\text { One hospital-based rapid access ambulatory heart failure clinic with ongoing care in the com- } \\
\text { munity from specialist heart failure nurses seeing patients with heart failure of any type. }\end{array}$} \\
\hline \multirow[t]{3}{*}{ General practitioner (P7) } & Cardiologist (P16) & \multirow{3}{*}{$\begin{array}{l}\text { Specialist heart failure } \\
\text { nurse (P24) }\end{array}$} \\
\hline & $\begin{array}{l}\text { Specialist heart failure nurses) (inter- } \\
\text { viewed together) (P17 and 18) }\end{array}$ & \\
\hline & Cardiac rehabilitation practitioner (P19) & \\
\hline \multicolumn{3}{|l|}{$\mathrm{P}=$ participant. } \\
\hline \multicolumn{3}{|c|}{$\begin{array}{l}\text { a Cardiac rehabilitation is a structured set of services that can be offered to people with heart failure to provide } \\
\text { physical and psychological help to preserve or resume their optimal functioning. }\end{array}$} \\
\hline
\end{tabular}


an initial coding framework that grew and developed as analysis proceeded. The codes were refined and built into wider categories. The 2 other interview sets (from the other 2 locations) were then examined, and the categories were further refined as confirming and disconfirming data were added and similarities and differences established. Overall themes were established and were checked against the 3 sets of interviews to ensure that all material had been included. The research team discussed the initial coding framework, as well as ideas for categories emerging from the data, and subsequently the final themes to ensure their credibility and confirmability. ${ }^{20}$

We drew on a combination of perspectives in the research team, including general practitioners with special interest in cardiovascular conditions, social scientists, and health service researchers in interpreting our data. Our professional advisory group included a cardiologist and a palliative care nurse consultant.

\section{RESULTS}

We identified 2 main thematic areas representing particular challenges to the clinicians: communication with patients, and communication within the team.

\section{Communication With Patients}

There was consensus that the term beart failure was unhelpful in explaining the diagnosis and prognosis to patients. Participants regarded it as a "loaded" term (participant $[\mathrm{P}] 5$, general practitioner), having an effect on patients that was similar to being told they had cancer. One participant was aware of a service that had adopted the more neutral term of beart function. In 1 location, heart failure had been standardized for use by the whole clinical team, so that everyone used the term consistently.

The participants found the task of explaining the diagnosis and prognosis of heart failure to patients challenging. They spoke about balancing the need to be honest about the seriousness of the condition, which could raise anxiety, with building trust to maintain hope and a positive outlook in the face of life-threatening illness. One participant explained how she would try to present treatment options as a way of managing symptoms and prolonging life, but not as a cure (P12, hospital specialist heart failure nurse).

Some participants spoke about addressing the question of prognosis over time, given the uncertainty about the course of the condition and in response to changing circumstances, particularly where patients might be approaching the end of their life:

I tend to play it along the lines of, well, we'll start some treatment and we'll see how things go.... But if I think things start to deteriorate in terms of symptom control..., then I think it is important to have a discussion... and that will be during the course of that relationship with the patient ( $\mathrm{P} 4$, general practitioner).

It was a common perception that this type of exchange between patients and clinicians did not take place often enough.

All participants recognized the importance of providing education to patients to help them manage their condition. Both secondary care physicians (specialists) and general practitioners recognized that they had a role in patient education, but time pressures during consultations restricted their contribution. Both sets of physicians were able to delegate responsibility for this aspect of care to the specialist heart failure nurses:

When it comes to a cardiology outpatient clinic, I think the first thing one has got to realize is that these clinic appointments are short.... A lot of patients when they are told they've got heart failure...will probably only remember 2 or 3 things that you say to them.... So I think that one of the major roles of the community nurses and the hospital specialist nurses is to take the patient from being aware of the diagnosis and how it's going to be treated...." (P11, cardiologist).

In each location, education represented a considerable portion of the specialist heart failure nurse's role. Participants agreed that education could be best delivered within the context of the ongoing relationship between the specialist nurse and the patient, in particular during the routine home visits, when patients were more relaxed and there was more time to assimilate information. Community matrons are experienced senior nurses working in the community with patients who have a serious, long-term or complex range of conditions. They were also able to provide this type of input:

You go into those very false situations where you're already fearful that [the patient can] only take in how much, a very tiny percentage of what that person just said to you. So I think that's where our education is, in a nice environment, which is usually their home. They feel relaxed and a little bit more in control because it's their environment...." (P21, community matron).

Participants acknowledged that not all patients would take up the education offered. Some patients would find the information challenging and difficult to assimilate. As a result, they would struggle with selfmanagement. These patients were more likely to be those whose first language was not English, those too ill to benefit from education or in denial about their condition, those attributing their condition to growing older, those with learning difficulties, and those experiencing cognitive decline or living with addictions. The specialist heart failure nurses spoke of the necessity to balance 
the education they offered patients with the patients' capacity to receive it. They tried to identify issues of importance to patients and to personalize the information. These clinicians emphasized that even when patients were able to understand information, it would still be necessary to repeat those messages over time:

To keep enforcing the education... but it's just dropping if you can, just sort of drip-feed it into them where every time you see them... (P22, community specialist heart failure nurse).

\section{Communication Within the Team}

To communicate well with their patients, the participants frequently mentioned the need to liaise and work closely with the wide range of clinicians involved in the care of heart failure patients across the diverse health care settings: specialist nurses; cardiologists and other medical specialty teams, including respiratory care/ medicine specialists, psychiatrists, and geriatricians; specialist palliative care teams, pharmacists ${ }_{i}$ community matrons and district nurses, general practitioners; ${ }_{i}$ cardiac rehabilitation teams and therapists; and continence and psychological therapists.

The specialist heart failure nurses in hospital settings aimed to discuss and agree on care proactively within the multidisciplinary team while their patients were still in hospital, which limited the time available to them. When patients were discharged from the hospital, specialist nurses in the community were eager to work together with secondary care clinicians and with patients' general practitioners and families to ensure that recommendations were acted upon. The need for clear, consistent communication among clinicians was frequently discussed, including the importance of a liaison between primary and specialty care to designate who would coordinate the patient's care:

We have to work out something between primary and secondary care as to who's going to take the lead.... I don't think it matters terribly which of us does as long as somebody does..." (P9, geriatrician).

In one location, a community matron explained how she fulfilled this function by working with the patient and other clinicians to make coordinated decisions about patient care and its continuity:

...that's where the case management comes in, that we pull all these people in, get all the right consultations for that particular condition, and then bring it all together, and then we can move forward (P21, community matron).

Community heart failure specialist nurses described how other conditions, such as chronic obstructive pulmonary disease, diabetes, chronic kidney disease, and low blood pressure, might affect the heart failure treatment and why they needed access to the expertise of others, including general practitioners and cardiologists. The participants recalled situations where heart failure management in the context of comorbidities created complexity, as medications came into conflict with each other, particularly in relation to heart failure and renal function. This conflict was expressed in terms of "competition" (P3, general practitioner) or "trade-off" (P24, community specialist heart failure nurse):

The drugs treat the heart, [but] it can more badly affect the kidneys. Look after the kidneys, and the heart may not be optimized in terms of clinical treatment, and there's a tightrope and sometimes it's a very tight tightrope... (P3, general practitioner). The participants saw the need for continued liaison and communication within the team to manage changes in drug regimens, especially when specialist nurses took on nonmedical prescribing. The participants described the dangers in titrating heart failure drugs without careful monitoring, and they expressed concerns about effective titration if the nurses did not supervise it after discharge and where responsibility lay to ensure that medications were optimized:

I'm not sure how many GPs [general practiitioners], when I will say to them I'm going to discharge them because they're stable, "Can you up titrate the ACE [angiotensin-converting enzymes] and the beta-blocker?" I'm not sure how much that [titration of drugs] happens..." (P23, community specialist heart failure nurse).

The participants recognized that patients can be seen as belonging to a single clinician or specialist team. The specialist heart failure nurses acknowledged the tensions around how best to provide advice to other clinicians who are not part of the heart failure service:

Some consultants do have very particular ways of, well, views really on things... I can understand that sometimes they must feel like "this is my patient, who are all these people that are coming in and advising me what to do with my patient" (P13, hospital specialist heart failure nurse).

The participants offered suggestions about how best to work effectively within multidisciplinary teams:

You want to keep good relationships really with the multidisciplinary team, and if you go around making decisions and not discussing it or letting people know, they'll understandably be a bit miffed, and we want to work in harmony with teams that look after patients and not be seen as a nuisance that comes along and interferes, but a useful resource to them. (P12, hospital specialist heart failure nurse).

In one location, general practitioners had very restricted access to specialist heart failure nurses 
because of lack of capacity. Other general practitioners, however, chose to manage patients single-handedly but then made prescribing decisions perceived to be incorrect by the specialist heart failure nurse or restricted patient access to specialist heart failure nursing services:

Not all of them [general practitioners] felt it was necessary to get a community heart failure nurse involved.... There will always be individuals who like to manage their patients a different way (P11, cardiologist).

Other general practitioners welcomed advice from specialist heart failure nursing services:

So she's [the specialist heart failure nurse] concerned about the heart failure management, she'll discuss it with her consultant, and then she'll ring me... and I'll take their advice on that." (P5, general practitioner).

\section{DISCUSSION}

Our study contributes to an understanding of the way specialist heart failure nurses view their role and how they contribute to caring for patients with heart failure, as well as how they are perceived by other clinicians. Our findings found substantial areas of agreement across settings and across the clinicians about the challenges that still remain, in both communicating with patients about their heart failure and about communicating with each other.

Education is frequently emphasized as essential in helping patients manage their condition. ${ }^{21,22}$ Our study participants believed in the importance of patient education, although specialist heart failure nurses and community matrons had more opportunity to deliver it, tailoring it to the needs of individual patients, than did general practitioners and specialists. Participants acknowledged, however, that education messages were not always received and acted upon by patients, which could lead to unplanned admissions. ${ }^{23}$

The primary care clinicians stressed the importance of working with colleagues across settings and specialties to improve patient care and outcomes. Specialist heart failure nurses were aware of comorbidities among their patients, the complexity comorbidities introduced, and the need for liaison with general practitioners and specialist physicians..$^{24,25}$ Similarly, medication management for heart failure was a challenge to the clinicians working outside specialty care. Specialist physicians voiced concerns about the levels of monitoring available in the community, affirmed by the participants in the primary care setting. Titration of medications emerged from the clinicians' accounts as a confusing area of care, in particular who would take the lead in implementation, although some specialist heart failure nurses had prescribing privileges.
The study participants recognized that the general practitioners may shoulder this responsibility; however, these physicians may require more information when patients are discharged from hospital. In addition, education and support from specialty care, combined with input from specialist heart failure nurses, would provide this support effectively and ensure that patients were receiving evidence-based interventions.

The general practitioners and specialist physicians we interviewed regarded the specialist heart failure nurses as the lead clinicians for their patients. Indeed, our findings emphasize the need for a key clinician, such as a specialist heart failure nurse, in managing these patients. These nurses were perceived as being able to bridge the gap between primary and secondary care by ensuring recommendations from specialist physicians were acted upon and by taking the lead in medication issues so that prescribing decisions reflected input from secondary care. In this way, they were seen to play a crucial role in ensuring coordination and continuity of care.

It was recognized that in some situations, however, general practitioners might seek to or need to manage patients unsupported, which might result in suboptimal care. The availability of specialist heart failure nursing and community matrons who could take on the responsibility for case management of heart failure patients varied across the 3 study locations.

\section{Strengths and Limitations of the Study}

We believe that the range of locations and clinicians in our study contributed to the breadth and richness of our data and make our study unique. The use of in-depth interviews allowed participants to talk freely, providing accounts of services that worked well and where change was perceived as necessary.

Although qualitative research does not set out to produce findings that are generalizable in the same way as quantitative research, by describing our methods, settings, and results, we believe the transferability of our findings to other settings can be judged ${ }^{20}$ and found relevant.

In one location we recruited patients to the wider study through general practitioners who were eager for their patients to participate and to be interviewed themselves. These physicians were already more confident and knowledgeable about managing heart failure patients. Thus, some of the views expressed in our study may not reflect wider opinions in general practice. We were unable to interview any clinicians providing renal care for heart failure patients.

Our participants agreed that heart failure management is challenging. Patients need more support to understand what their heart failure means and how 
it will be managed, as well as to plan for the future. Although participants agreed that patient education is needed, they stressed the importance of ongoing, tailored input for patients and families provided by a clinician. Advocated were clearer lines of responsibility, a multidisciplinary involvement with regard to managing drug regimens, and more education for clinicians regarding comorbidities and medications. A key clinician, such as a specialist heart failure nurse, who could take the lead in coordinating services for heart failure patients was regarded as vital in ensuring continuity and quality of care.

To read or post commentaries in response to this article, see it online at http://www.annfammed.org/content/13/5/466.

Key words: heart failure; diagnosis/prognosis; patient education; comorbidities; medications; unplanned hospital admissions

Submitted November 27, 2014; submitted, revised, July 6, 2015; accepted July 8, 2015.

Funding support: This work was supported by the National Institute for Health Research School for Primary Care Research (NIHR SPCR) [UKCRN ID: 12226 to SP]. Dr Sanders was supported in the preparation/submission of this article by the Translating Knowledge into Action Theme of the National Institute for Health Research Collaboration for Leadership in Applied Health Research and Care Yorkshire and Humber (NIHR CLAHRC YH). http://www.clahrc-yh.nir.ac.uk. Dr Lasserson was funded by the NIHR Oxford Biomedical Research Centre.

Disclaimer: The views expressed are those of the authors and not necessarily those of the NHS, the NIHR or the Department of Health.

Acknowledgments: We would like to thank all of the clinicians in the 3 participating centers who contributed to the HoldFAST study.

Supplementary materials: Available at http://www.AnnFamMed. org/content/13/5/466/suppl/DC1/

\section{References}

1. Cowie MR, Wood DA, Coats AJ, et al. Incidence and aetiology of heart failure; a population-based study. Eur Heart J. 1999;20(6): 421-428.

2. Hobbs FD, Roalfe AK, Davis RC, Davies MK, Hare R; Midlands Research Practices Consortium (MidReC). Prognosis of all-cause heart failure and borderline left ventricular systolic dysfunction: 5 year mortality follow-up of the Echocardiographic Heart of England Screening Study (ECHOES). Eur Heart J. 2007;28(9):1128-1134.

3. Iqbal J, Francis L, Reid J, Murray S, Denvir M. Quality of life in patients with chronic heart failure and their carers: a 3-year follow-up study assessing hospitalization and mortality. Eur J Heart Fail. 2010;12(9):1002-1008.

4. Stewart S. Increased health care utilisation and costs: heart failure in the 21st century. In: Stewart S, Blue L, eds. Improving Outcomes in Chronic Heart Failure: Specialist Nurse Intervention From Research to Practice. London: BMJ Books; 2004:3-26.

5. Health and Social Care Information Centre. Hospital Episode Statistics 2012/2013. http://www.hscic.gov.uk. Accessed Jan 23, 2014.
6. Department of Health. Modernising Nursing Careers - Setting the Direction. London: Department of Health; 2006. http://www.gov. scot/resource/doc/146433/0038313.pdf.

7. Department of Health. Developing Services for Heart Failure. London, England: Department of Health; 2003.

8. Horne R, Coombes I, Davies G, Hankins M, Vincent R. Barriers to optimum management of heart failure by general practitioners. Br J Gen Pract. 1999;49(442):353-357.

9. Hobbs FDR, Jones MI, Allan TF, Wilson S, Tobias R. European survey of primary care physician perceptions on heart failure diagnosis and management (Euro-HF). Eur Heart J. 2000;21(22):1877-1887.

10. Houghton AR, Cowley AJ. Why are angiotensin converting enzyme inhibitors underutilised in the treatment of heart failure by general practitioners? Int J Cardiol. 1997;59(1):7-10.

11. Hobbs FDR. Management of heart failure: evidence versus practice. Does current prescribing provide optimal treatment for heart failure patients? Br J Gen Pract. 2000;50(458):735-742.

12. Fuat A, Hungin APS, Murphy JJ. Barriers to accurate diagnosis and effective management of heart failure in primary care: qualitative study. BMJ. 2003;326(7382):196.

13. Khunti K, Hearnshaw H, Baker R, Grimshaw G. Heart failure in primary care: qualitative study of current management and perceived obstacles to evidence-based diagnosis and management by general practitioners. Eur J Heart Fail. 2002;4(6):771-777.

14. Rogers AE, Addington-Hall JM, Abery AJ, et al. Knowledge and communication difficulties for patients with chronic heart failure: qualitative study. BMJ. 2000;321(7261):605-607.

15. Barnes S, Gott M, Payne S, et al. Communication in heart failure: perspectives from older people and primary care professionals. Health Soc Care Community. 2006;14(6):482-490.

16. Blue L, Lang E, McMurray JJ, et al. Randomised controlled trial of specialist nurse intervention in heart failure. BMJ. 2001;323(7315): 715-718.

17. MacKenzie E, Smith A, Angus N, Menzies S, Brulisauer F, Leslie SJ. Mixed-method exploratory study of general practitioner and nurse perceptions of a new community based nurse-led heart failure service. Rural and Remote Health. 2010:10(4):1510.1.

18. Strauss A, Corbin J. Basics of Qualitative Research: Techniques and Procedures for Developing Grounded Theory. 2nd ed. Thousand Oaks, CA: Sage Publications; 1990.

19. Silverman D. Doing Qualitative Research. 3rd ed. London: Sage Publications; 2010.

20. Lincoln YS, Guba EH. Naturalistic Inquiry. Beverly Hills, CA: Sage Publications; 1985.

21. National Institute for Health and Care Excellence (NICE). Chronic Heart Failure: Management of Chronic Heart Failure in Adults in Primary and Secondary Care. NICE Clinical Guideline 108. London, England: National Institute for Health and Care Excellence; 2010.

22. Moser DK, Dickson V, Jaarsma T, Lee C, Stromberg A, Riegel B. Role of self-care in the patient with heart failure. Curr Cardiol Rep. 2012;14(3):265-275.

23. Horowitz CR, Rein SB, Leventhal H. A story of maladies, misconceptions and mishaps: effective management of heart failure. Soc Sci Med. 2004;58(3):631-643.

24. Masoudi FA, Krumholz HM. Polypharmacy and comorbidity in heart failure. BMJ. 2003;327(7414):513-514.

25. Hancock HC, Close H, Fuat A, Murphy JJ, Hungin APS, Mason JM. Barriers to accurate diagnosis and effective management of heart failure have not changed in the past 10 years: a qualitative study and national survey. BMJ Open. 2014;4(3):e003866. 